\title{
Surgical and clinical strategies in the management of thyroid medullary carcinoma in children with and without ret proto- oncogene mutations
}

\author{
Özlem Boybeyi-Türer ${ }^{1}$, Doğuş Vurallı², İbrahim Karnak ${ }^{1}$, Nazlı Gönç², Emel Şule Yalçın¹, \\ Diclehan Orhan $^{3}$, Nurgün Kandemir ${ }^{2}$, Feridun Cahit Tanyel ${ }^{1}$ \\ Department of ${ }^{1}$ Pediatric Surgery and Divisions of ${ }^{2}$ Pediatric Endocrinology, and ${ }^{3}$ Pediatric Pathology, Department of \\ Pediatrics, Hacettepe University, Faculty of Medicine, Ankara, Turkey E-mail: ikarnak@hacettepe.edu.tr \\ Received: 15th February 2016, Revised: 18th March 2016, Accepted: 12th April 2016
}

\begin{abstract}
SUMMARY: Boybeyi-Türer Ö, Vurallı D, Karnak İ, Gönç N, Yalçın EŞ, Orhan D, Kandemir N, Tanyel FC. Surgical and clinical strategies in the management of thyroid medullary carcinoma in children with and without ret proto-oncogene mutations. Turk J Pediatr 2016; 58: 436-441.

Medullary thyroid carcinoma (MTC) may arise sporadically or in familial manner. We presented sporadic and familial cases with MTC in order to raise awareness on management of such patients. Three medullary thyroid carcinoma (MTC) cases were presented. Case 1 had RET634 mutation; managed with total thyroidectomy (TT) and cervical lymph node dissection (CLND). Case 2 had RET804 mutation; managed with prophylactic TT. Case 3 had thyroid nodule; managed with TT and CLND. Case 1 had micro-carcinomatosis foci, Case 2 had normal thyroid tissue in histopathological examination and Case 3 had medullary thyroid carcinoma with tumor negative surgical borders. Case 1 was re-operated for persisting focus of disease. Follow-up of cases were uneventful. Clinicians and surgeons should be aware of critical timing for surgery and various surgical and clinical strategies in the management of MTC in children.
\end{abstract}

Key words: medullary thyroid carcinoma, multiple endocrine neoplasia, surgery, RET proto-oncogene.

Medullary thyroid carcinoma (MTC) is an uncommon neuroendocrine tumor originated from calcitonin-secreting parafollicular or $\mathrm{C}$ cells of the thyroid ${ }^{1,2}$. MTC arises not only sporadically but also in a hereditary manner associated with multiple endocrine neoplasia type 2 (MEN2) syndromes and familial medullary thyroid carcinoma (FMTC). MEN 2A is characterized by MTC, pheochromocytoma and primary hyperparathyroidism, whereas MEN 2B is characterized by MTC, pheochromocytoma and mucosal ganglioneuromas ${ }^{3}$. While the risk of developing MTC in MEN 2A is $90-100 \%$, the risk of developing pheochromocytoma and hyperparathyroidism is $50 \%$ and $20-$ $30 \%$ respectively ${ }^{1}$. Various variant forms such as MEN2A+Hirschsprung disease, MEN2A+cutaneous lichen amyloidosis are also described in association with MEN2A. On the other hand, MTC is present in $100 \%$ of the cases with MEN2B and marfanoid habitus is present in $100 \%$ and pheochromocytoma and mucosal ganglioneuroma accompany those in $50 \%$ each $^{3}$.

Since the relationship between RET protooncogene mutation and MTC, especially familial one, is well-known, the DNA analysis has become an essential routine investigation in patients with MTC. The aggressiveness of MTC varies according to the mutated codon of RET proto-oncogene. Therefore, the patients are classified into different risk groups and managed accordingly 4 . The American Thyroid Association (ATA) established current management recommendations with the aim of preventing MTC before it becomes an aggressive metastatic disease ${ }^{4}$. On the other hand, it is also important to minimize the surgical risks of total thyroidectomy (TT). Therefore, timing of prophylactic TT has also 
been defined according to the risk groups of RET mutations in MEN ${ }^{4}$. Sporadic MTCs are generally seen after 20 years of age and recommended to be managed with TT before development of metastasis to other organs ${ }^{1}$.

Herein, we presented three cases; two of which had previously known RET proto-oncogene mutations of different codons and the other had no known mutation in order to raise awareness on surgical and clinical management of such patients.

\section{Case Reports}

\section{Case 1}

A 6-year-old boy was referred to our hospital with a strong family history of MTC. His father, his paternal uncle, his grandfather and his two cousins were diagnosed with MTC. Medical history of the patient did not show evidence of Hirschsprung's disease. The genetic testing of the patient revealed heterozygosity of codon 634 mutation (C634Y). The preoperative laboratory examinations revealed that the patient was euthyroid under $25 \mu \mathrm{g} /$ day levothyroxine treatment. The serum calcitonin level was elevated $(149 \mathrm{pg} / \mathrm{ml}, \mathrm{N}$ : $0-18)$. The parathyroid hormone level (PTH) was $18.6 \mathrm{pg} / \mathrm{ml}$ (N: 12-88), serum total calcium level was $10.1 \mathrm{mg} / \mathrm{dl}$ ( $\mathrm{N}: 8.4-10.2$ ), ionized calcium was $1.2 \mathrm{mmol} / \mathrm{dl}$ ( $\mathrm{N}: 1.23-1.38$ ), serum phosphorus level was $5.4 \mathrm{mg} / \mathrm{dl}(\mathrm{N}$ : 2.7-4.9), and alkaline phosphotase was 154 $\mathrm{U} / \mathrm{L}(\mathrm{N}:<390)$. The 24 -hour urine analysis of metanephrine and normetanephrine values were $74 \mu \mathrm{g} / \mathrm{d}(\mathrm{N}: 52-341)$ and $89 \mu \mathrm{g} / \mathrm{d}(\mathrm{N}$ : 88-444) respectively. The thyroid ultrasound (US) revealed normal findings except bilateral jugular and cervical lymphadenopathies. The parathyroid scintigraphy revealed normal findings. The whole body examination with sestamibi scintigraphy revealed bilateral jugular and cervical lymph nodes involvement (Fig. 1). Abdominal US was normal.

The intraoperative exploration revealed that thyroid gland was normal macroscopically. TT was performed and bilateral recurrent laryngeal nerves and parathyroid glands were preserved. Central compartment and bilateral lateral-cervical lymph node dissection (modified neck lymph node dissection) was performed. His postoperative follow-up was uneventful and he was discharged on $3^{\text {rd }}$ postoperative

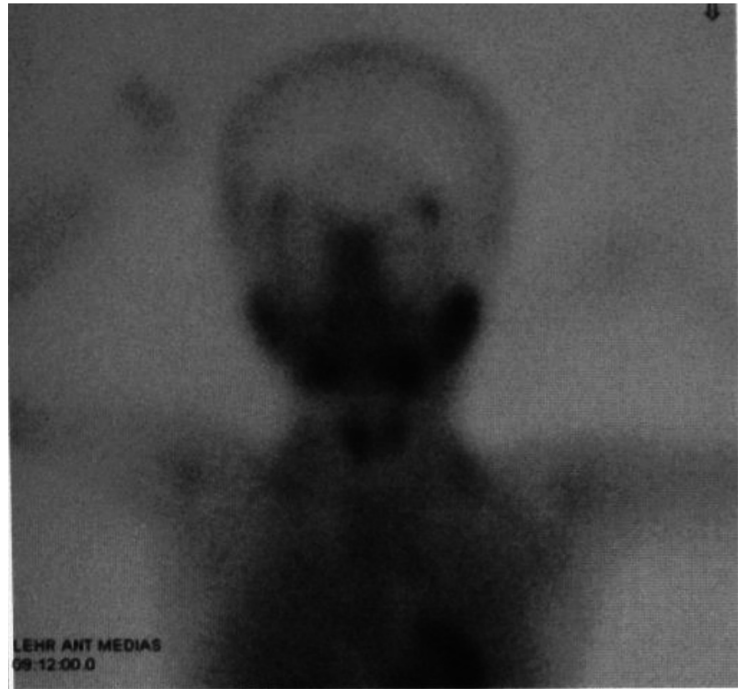

Fig. 1. The sestamibi scintigraphy of Case 1 revealing bilateral jugular and cervical lymph node involvement; the black doted areas revealing positive involvement of bilateral jugular and cervical lymph nodes.

day. The histopathological examination revealed 3 foci of thyroid medullary micro-carcinoma and metastasis in five of lymph nodes located next to thyroid gland. The tumor cells of micro-carcinoma foci were positively stained with chromogranine, CD56 and calcitonin; and negatively stained with thyroglobulin $(\mathrm{Tg})$ (Fig. 2). Postoperative calcitonin level was 28.1 $\mathrm{pg} / \mathrm{ml}(\mathrm{N}: 0-18)$ and $\mathrm{Tg}$ level was $4.25 \mathrm{ng} /$ $\mathrm{ml}(\mathrm{N}: 0.15-50)$. Calcitonin levels increased gradually to $43.1 \mathrm{pg} / \mathrm{ml}$ and ultrasound revealed a suspected residual tissue of $4 \times 8 \mathrm{~mm}$. Therefore, re-exploration was performed after labeling of the focus with ${ }^{131}$ Iodine injection and the focus was excised with the aid of gamma probe guidance during operation. The histopathological examination revealed MTC metastasis in the excised lymph node. The patient is still under follow-up uneventfully.

\section{Case 2}

A 13-year-old boy was referred to our hospital with a strong family history of MTC. His father, his paternal uncle, his 4 paternal aunts, three siblings were diagnosed with MTC. Medical history of the patient did not show evidence of Hirschsprung's disease. Upon physical examination, he had no goiter. No nodules were detected in the thyroid ultrasonography and thyroid dimensions were normal. The genetic testing of the patient revealed heterozygosity of codon 804 mutation (Exon 14 p. V804M 

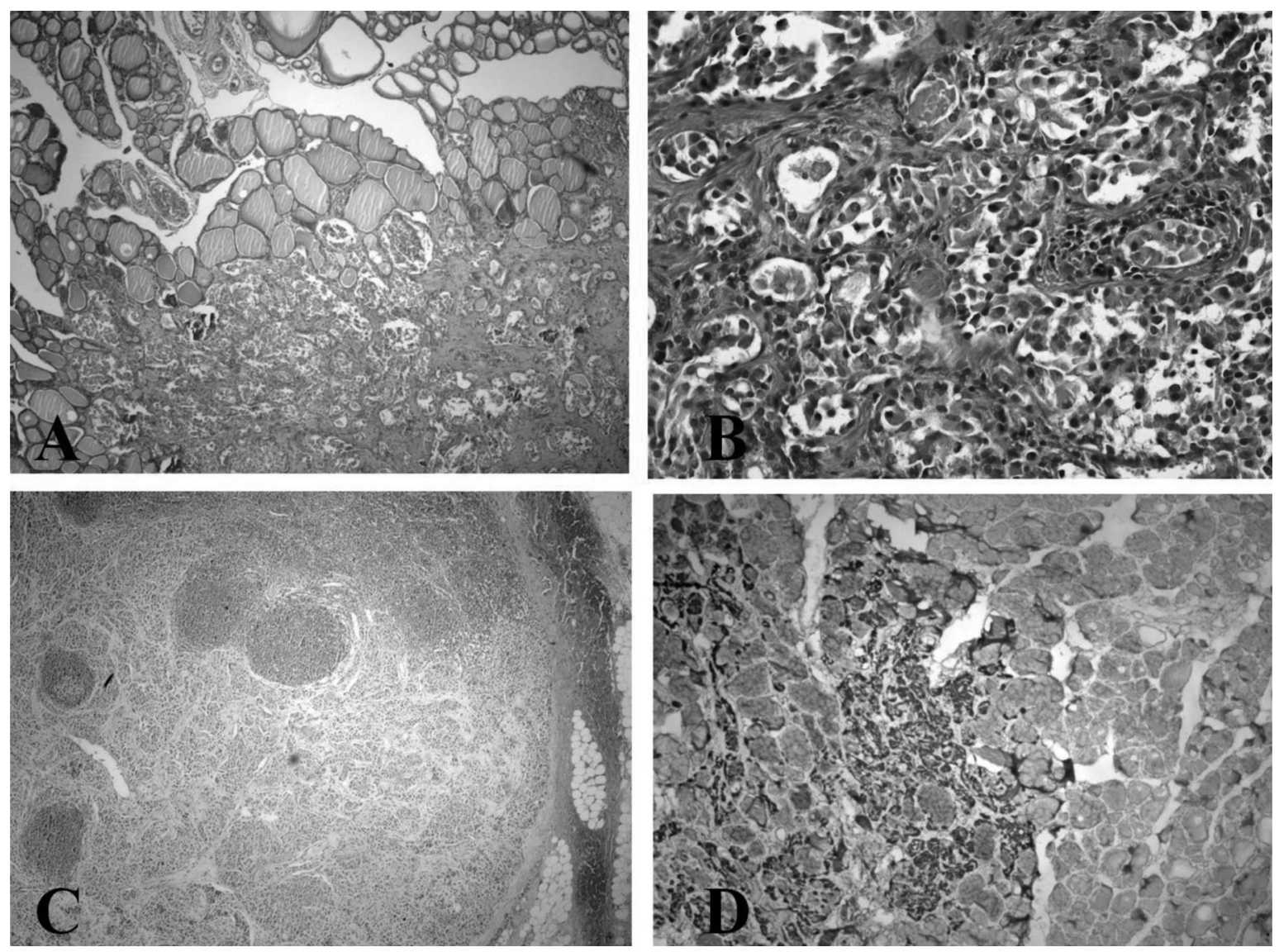

Fig. 2. Histopathologic examination of first case;

2A. Tumor with a diameter of $0.5 \mathrm{~cm}$ in thyroid tissue without a capsule (HE, X40).

2B. Tumor cells of thyroid medullary carcinoma shown in Fig 2A (HE, X200).

2C. Metastasis of thyroid medullary carcinoma to cervical lymph node (HE, X100).

2D. Calcitonin positivity of tumor cells of thyroid medullary carcinoma (immune-peroxidase, X40).

(c.G2410A)). The preoperative laboratory examinations revealed that the patient was euthyroid. The serum calcitonin level was normal (3.52 ng/L, N: 0-18). The parathyroid hormone level (PTH) was $72.9 \mathrm{pg} / \mathrm{ml}$ (N: 1288 ), serum total calcium level was $9.9 \mathrm{mg} / \mathrm{dl}$ (N: 8.4-10.2), ionized calcium was $1.3 \mathrm{mmol} / \mathrm{dl}$ (N: 1.23-1.38), serum phosphorus level was 4.5 $\mathrm{mg} / \mathrm{dl}(\mathrm{N}: 2.7-4.9)$, and alkaline phosphatase was $304 \mathrm{U} / \mathrm{L}(\mathrm{N}$ : <390). The 24-hour urine analysis of metanephrine and normetanephrine was within normal limits.

This case had single mutation in codon 804 and thus accepted to be in the lowest risk group for development of MTC. The cases in this risk group are recommended to have annual calcitonin and cervical US follow-up and to undergo prophylactic thyroidectomy no later than 10 years of age. Therefore, thyroidectomy was performed and bilateral recurrent laryngeal nerve and parathyroid glands were preserved. The intraoperative exploration revealed that thyroid gland was normal macroscopically. His postoperative follow-up was uneventful and he was discharged on $3^{\text {rd }}$ postoperative day. The histopathological examination revealed normal thyroid gland. The case is being followed-up on calcium and PTH tests for hyperparathyroidism and with metanephrine/ normetanephrine screening in 24-hour urine for pheochromocytoma.

\section{Case 3}

A 16-year-old boy was referred to our hospital with a palpable mass in his neck. He had no systemic symptoms such as: headaches, sweating, hot flashes, red flushed face, fatigue, weight loss, sense of palpitation, diarrhea, vomiting, or abdominal pain. His past medical history and family history were unremarkable. 
There were no family members with a history of MTC. His blood pressure and pulse rate were within normal ranges and he had no mucosal neurinomas. The laboratory examinations revealed that the patient was euthyroid. The serum calcitonin level was $>100 \mathrm{pg} / \mathrm{ml}(3.52$ $\mathrm{ng} / \mathrm{L}, \mathrm{N}: 0-18)$, thyroglobulin was $39.6 \mathrm{ng} / \mathrm{ml}$ (N: 0-60), Carcinoembryonic antigen (CEA) was $9.2 \mathrm{ng} / \mathrm{ml}$ (normal level in healthy men: $0.37-3.3 \mathrm{ng} / \mathrm{ml}$ and $<6.2 \mathrm{ng} / \mathrm{ml}$ in cigarette smokers).

Ultrasonography revealed heterogeneous nodule measuring $28 \times 34 \mathrm{~mm}$ with cystic and solid regions in the left thyroid and there was no pathological lymph nodes. Fine needle aspiration biopsy was performed and histopathological examination revealed medullary thyroid carcinoma. The preoperative evaluation of the patients who were diagnosed to have MTC with a fine needle aspiration biopsy should include a clinical and laboratory screening for pheochromocytoma and hyperparathyroidism in addition to calcitonin and CEA measurements ${ }^{4}$. Thyroid cancer can be the index case of the syndromes. Serum calcium level was $9.4 \mathrm{mg} /$ dl (N: 8.5-10.2), phosphorus level was 4.6 $\mathrm{mg} / \mathrm{dl}$ (N: 2.5-4.5), serum ALP was $155 \mathrm{IU} / \mathrm{L}$ (N: 52-171), and PTH level was $59.4 \mathrm{pg} / \mathrm{ml}$ $(\mathrm{N}:$ 10-65). The 24-hour urine catecholamine metabolites were normal. Additionally, for the same reason, all cases should be evaluated in terms of the RET proto-oncogene "germline" mutations even if no medullary cancer is present in the family history. No mutation was present in the RET proto-oncogene in this case.

Thyroidectomy and a central neck dissection were performed. Postoperative serum calcitonin level was $<2 \mathrm{ng} / \mathrm{ml}$ and the CEA level was $0.5 \mathrm{ng} / \mathrm{ml}$. The case is still under follow-up with calcitonin measurement every six months for four years without any recurrence of the disease.

\section{Discussion}

Medullary thyroid carcinoma (MTC), encountered in children and adolescents, is generally thought to be the hereditary form secondary to a mutation in the RET protooncogene. The occurrence of medullary thyroid carcinoma in MEN2 and FMTC syndromes is almost certain and it may become metastatic carcinoma even in the early stage of the disease ${ }^{1,5,6}$. The presentation and prognosis of the disease depends on the type of mutation on RET proto-oncogene ${ }^{1,6}$. Therefore, genetic testing of all family members even before 5 years of age is crucial if there is a known family member. Case 1 and 2 were diagnosed by genetic testing because they have relatives diagnosed as MTC. Case 3 was a sporadic MTC without a known RET mutation.

Germline RET mutations are present in $25 \%$ of the cases, which are called hereditary MTC. Somatic (acquired) RET proto-oncogene mutations at exon $10,11,15$, and 16 are present in $65 \%$ of cases with sporadic $\mathrm{MTC}^{7}$, ${ }^{8}$. Therefore, genetic screening for the germline RET oncogene is recommended in all cases. When an index case is found to be positive for a germline mutation, all other family members should be screened for this mutation and genetic counseling should be provided. The germline RET proto-oncogene mutation has been reported in $95 \%$ of cases with MEN2A and $2 \mathrm{~B}$ and $88 \%$ of cases with FMTC, respectively 9 , 10. When a germline RET mutation is found to be positive and thyroid examination is normal, calcitonin measurement should be performed starting six months of age in cases with MEN2B and at 3 years of age in cases with MEN2A and FMTC. Similarly, a detailed neck ultrasound examination should be performed immediately in all cases with MEN2B, and after 3-5 years of age in cases with MEN2A and FMTC ${ }^{4}$.

Prophylactic thyroidectomy should be planned according to the degree of risk of the mutation detected in the family members. It should be kept in mind that the most effective treatment of MTC is prevention before it develops by TT. However, timing of TT is the critical issue since there is a delicate balance between treatment of MTC and complications of TT. The American Thyroid Association guidelines defined four risk categories of MTC for timing of $\mathrm{TT}^{4}$. TT should be performed in risk level D (MEN 2B cases with mutations in codons 918, 883 and tandem mutations in codons 804-805, 804-806, 804-904) within first year of life; in risk level C (Mutations in codons 630 and $634)$ before 5 years of age preferably between 2-4 years of age; in risk level B (Mutations in codons 609, 611, 618, 620, 630 and tandem mutations in codons 804-778) before 6 years 
of age; in risk level A (mutations in codons 533, 635, 649, 666, 768, 790, 791, 891, 912, and single mutation in codon 804 ) before 10 years of age ${ }^{1,4,11-19}$.

In the literature, it was reported that prophylactic central lymph node dissection is not necessary in all cases ${ }^{1,4,6}$. But, central neck lymph node dissection is advised to be performed if there is evidence of lymph node metastasis, elevated serum calcitonin level $>40 \mathrm{pg} / \mathrm{ml}$, nodule dimension $>5 \mathrm{~mm}$ or in cases older than 1 year of age who are in the high risk group $1,15,18,20,21$. Case 1 had codon 634 mutation and TT was performed when he was 6 years of age. In the present study, we performed lymph node dissection in Case 1 because there were palpable cervical lymph nodes, and ultrasound and scintigraphy revealed pathological lymph node involvement and serum calcitonin level was higher than 40 $\mathrm{pg} / \mathrm{ml}$ (149 pg/ml). Case 2 had codon 804 mutation and TT was performed when he was 13 years of age. We did not perform central lymph node dissection in Case 2 since there were no pathological findings in preoperative laboratory and radiological examinations. Unfortunately, we operated the patients at an age later than the one recommended in ATA guidelines because they were admitted to our hospital late. According to the ATA guidelines, prophylactic TT may be delayed if there is no evidence of lymph node metastasis, basal calcitonin level is under $40 \mathrm{pg} / \mathrm{ml}$, and thyroid nodules in ultrasound are smaller than $5 \mathrm{~mm}$ ${ }^{4}$. However, there are several reports against the delay criteria of ATA guidelines. Morris et al. $^{2}$ reported that US should not be used to determine timing of surgery since it is not reliable enough to show microscopic MTC. On the other hand, delaying surgical management more than recommended in guidelines is reported as the only predictor factor for persistence and recurrence of disease $22-24$.

Post-operatively, close follow-up is recommended in MTC patients for recurrence of MTC,22-24. The serum calcitonin level and CEA are the tumor markers used in the postoperative follow up of MTCs ${ }^{25,26}$. Cases with a normal postoperative serum CEA and a low calcitonin level that cannot be measured are accepted as biochemically cured and have the best prognosis. According to the guidelines calcitonin levels should be measured 2-3 months after the first operation $^{27}$. A cure is achieved when the basal calcitonin level is at an unmeasurable level and then, a routine calcitonin measurement should be performed in every six months for the first two to three years, followed by annual calcitonin measurements. A high calcitonin level in six months or more after the operation indicates residual disease. In the postoperative follow-up of Case 1 had gradually elevating calcitonin levels and underwent excision of residual focus. Recurrence usually occurs 5-7 years after the surgery; therefore patients should be followed for a long period ${ }^{1,28}$. The follow-up period is 2 months in Case 1, 2 years in Case 2 and 4 years in Case 3 in the present study. Therefore, it might not be true to have a firm conclusion on the long-term results of these cases.

In addition post-operative follow-up is recommended for the other components of MEN syndromes. Since the risks of pheochromocytoma and hyperparathyroidism are high in carriers of codons 630 and 634 mutations, they should be annually followed-up by checking free metanephrine and normetanephrine in plasma or 24-hour urine catecholamine metabolites for pheochromocytoma and serum calcium and PTH measurement for hyperparathyroidism after 8 years of age and starting after 20 years in carriers of other mutations ${ }^{29,30}$. Both Case 1 and Case 2 will be followed up for the components of MEN syndromes accordingly since their mutations carry the risk of developing these diseases.

Herein, we presented one sporadic MTC case and two late-admitted hereditary MTC cases; one of whom was managed by TT and cervical lymph node dissection and the other was managed by prophylactic TT. Long-term results are also needed to have a firm conclusion. By means of these cases, an approach to MTC in childhood and RET oncogene positivity was discussed. It was aimed to raise awareness on various management strategies in the treatment of MTC and critical timing for surgery which is important for better prognosis and survival.

\section{REFERENCES}

1. Tavares MR, Toledo SP, Montenegro FL, et al. Surgical approach to medullary thyroid carcinoma associated with multiple endocrine neoplasia type 2 . Clinics (Sao Paulo) 2012; 67: 149-154. 
2. Morris LF, Waguespack SG, Edeiken-Monroe BS, et al. Ultrasonography should not guide the timing of thyroidectomy in pediatric patients diagnosed with multiple endocrine neoplasia syndrome $2 \mathrm{~A}$ through genetic screening. Ann Surg Oncol 2013; 20: 53-59.

3. Romei C, Pardi E, Cetani F, Elisei R. Genetic and clinical features of multiple endocrine neoplasia types 1 and 2. J Oncol 2012: 705036.

4. Kloos RT, Eng C, Evans DB, et al. Medullary thyroid cancer: management guidelines of the American Thyroid Association. Thyroid 2009; 19: 565-612.

5. Wiersinga WM. Thyroid cancer in children and adolescents--consequences in later life. J Pediatr Endocrinol Metab 2001; 14: 1289-1296.

6. Spinelli C, Di Giacomo M, Costanzo S, Elisei R, Miccoli P. Role of RET codonic mutations in the surgical management of medullary thyroid carcinoma in pediatric age multiple endocrine neoplasm type 2 syndromes. J Pediatr Surg 2010; 45: 1610-1616.

7. Pacini F, Castagna MG, Cipri C, Schlumberger M. Medullary thyroid carcinoma. Clin Oncol (R Coll Radiol) 2010; 22: 475-485.

8. Marsh DJ, Learoyd DL, Andrew SD, et al. Somatic mutations in the RET proto-oncogene in sporadic medullary thyroid carcinoma. Clin Endocrinol (Oxf) 1996; 44: 249-257.

9. Elisei R, Romei C, Cosci B, et al. RET genetic screening in patients with medullary thyroid cancer and their relatives: experience with 807 individuals at one center. J Clin Endocrinol Metab 2007; 92: 4725-4729.

10. Moline J, Eng C. Multiple endocrine neoplasia type 2: an overview. Genet Med 2011; 13: 755-764.

11. Miyauchi A, Futami H, Hai N, et al. Two germline missense mutations at codons 804 and 806 of the RET proto-oncogene in the same allele in a patient with multiple endocrine neoplasia type $2 \mathrm{~B}$ without codon 918 mutation. Jpn J Cancer Res 1999; 90: 1-5.

12. Hansford JR, Mulligan LM. Multiple endocrine neoplasia type 2 and RET: from neoplasia to neurogenesis. J Med Genet 2000; 37: 817-827.

13. Donis-Keller H, Dou S, Chi D, et al. Mutations in the RET proto-oncogene are associated with MEN 2A and FMTC. Hum Mol Genet 1993; 2: 851-856.

14. Mulligan LM, Kwok JB, Healey CS, et al. Germ-line mutations of the RET proto-oncogene in multiple endocrine neoplasia type 2A. Nature 1993; 363: 458460 .

15. Jarzab B, Szpak-Ulczok S, Wloch J, Czarniecka A, Krajewska J. Timing and criteria for prophylactic thyroidectomy in asymptomatic RET carriers - the role of Ct serum level. Thyroid Res 2013; 6: S9.

16. Salehian B, Samoa R. RET gene abnormalities and thyroid disease: who should be screened and when. J Clin Res Pediatr Endocrinol 2013; 5: 70-78.

17. Elisei R, Romei C, Renzini G, et al. The timing of total thyroidectomy in RET gene mutation carriers could be personalized and safely planned on the basis of serum calcitonin: 18 years experience at one single center. J Clin Endocrinol Metab 2012; 97: 426-435.
18. Machens A, Dralle H. Prophylactic thyroidectomy in RET carriers at risk for hereditary medullary thyroid cancer. Thyroid 2009; 19: 551-554.

19. Frank-Raue K, Buhr H, Dralle H, et al. Long-term outcome in 46 gene carriers of hereditary medullary thyroid carcinoma after prophylactic thyroidectomy: impact of individual RET genotype. Eur J Endocrinol 2006; 155: 229-236.

20. Marsh DJ, McDowall D, Hyland VJ, et al. The identification of false positive responses to the pentagastrin stimulation test in RET mutation negative members of MEN 2A families. Clin Endocrinol (Oxf) 1996; 44: 213-220.

21. Machens A, Lorenz K, Dralle H. Individualization of lymph node dissection in RET (rearranged during transfection) carriers at risk for medullary thyroid cancer: value of pretherapeutic calcitonin levels. Ann Surg 2009; 250: 305-310.

22. Schreinemakers JM, Vriens MR, Valk GD, et al. Factors predicting outcome of total thyroidectomy in young patients with multiple endocrine neoplasia type 2: a nationwide long-term follow-up study. World J Surg 2010; 34: 852-860.

23. Niederle B, Sebag F, Brauckhoff M. Timing and extent of thyroid surgery for gene carriers of hereditary C cell disease--a consensus statement of the European Society of Endocrine Surgeons (ESES). Langenbecks Arch Surg 2014; 399: 185-197.

24. Grubbs EG, Waguespack SG, Rich TA, et al. Do the recent American Thyroid Association (ATA) Guidelines accurately guide the timing of prophylactic thyroidectomy in MEN2A? Surgery 2010; 148: 13021309.

25. Cohen R, Campos JM, Salaun C, et al. Preoperative calcitonin levels are predictive of tumor size and postoperative calcitonin normalization in medullary thyroid carcinoma. Groupe d'Etudes des Tumeurs a Calcitonine (GETC). J Clin Endocrinol Metab 2000; 85: 919-922.

26. Watson CG, Felling J, Maceachern DG. Objective Draw-a-Person scales: an attempted cross-validation. J Clin Psychol 1967; 23: 382-386.

27. Jimenez C, Hu MI, Gagel RF. Management of medullary thyroid carcinoma. Endocrinol Metab Clin North Am 2008; 37: 481-496.

28. Skinner MA, Moley JA, Dilley WG, Owzar K, Debenedetti MK, Wells SA, Jr. Prophylactic thyroidectomy in multiple endocrine neoplasia type 2A. N Engl J Med 2005; 353: 1105-1113.

29. Rodriguez JM, Balsalobre M, Ponce JL, et al. Pheochromocytoma in MEN 2A syndrome. Study of 54 patients. World J Surg 2008; 32: 2520-2526.

30. Nguyen L, Niccoli-Sire P, Caron P, et al. Pheochromocytoma in multiple endocrine neoplasia type 2: a prospective study. Eur J Endocrinol 2001; 144: $37-44$ 